\title{
Characterisation of C-shape pultruded fibre reinforced polymer for bridge structures
}

\author{
Winarputro Adi Riyono ${ }^{1}$ (D) Johan Nasiri ${ }^{2}$
}

(c) Springer Nature Switzerland AG 2019

\begin{abstract}
The development of polymer technology has been increased for the past 20 years. Most of the polymer based product is available for aviation, automotive, industrial, and infrastructure purposes include bridges. But, information concern with the used of polymer materials for bridge structures are scattered. In this paper, characterisation was made to investigate the applicability of pultruded fibre reinforced polymer (PFRP) for bridges as structural elements. Several experiments test was then carried out to determine the physical and mechanical properties of PFRP. Some results are compared with the available pre-standard of PFRP for structures. Afterwards, an ageing test was undertaken to observe the effect of temperature on the mechanical properties of PFRP. Comparison with the pre-standard of PFRP for structures show that the physical characteristics are satisfied the minimum requirements. In the mechanical part, the tensile and flexural properties of tested PFRP are conform with the pre-standard of PFRP, whereas the compressive strength was below the recommendation of the pre-standard. From ageing test under high temperature, the PFRP strength is possible to increase or decrease. Enhancement of mechanical strength could be generated by polymer cross-linking reactions which takes place after the production of PFRP and accelerated by high temperature. While, the decreasing of strength is related to the delamination process of the fibre.
\end{abstract}

Keywords PFRP · Physical test · Mechanical test · Ageing · Cross-linking

\begin{tabular}{ll}
\multicolumn{2}{l}{ Abbreviations } \\
AASHTO & $\begin{array}{l}\text { American Association of State Highway and } \\
\text { Transportation Officials }\end{array}$ \\
ASTM & American Society for Testing and Materials \\
ATR & Attenuated total reflectance \\
EDS & Energy dispersive -ray spectroscopy \\
ESCR & Environmental stress cracking resistance \\
FTIR & Fourier transform infrared spectroscopy \\
ISO & $\begin{array}{l}\text { International Organization for } \\
\end{array}$ \\
MMA & Standardization \\
Methyl methacrylate \\
PFRP & Pultruded fibre reinforced polymer \\
SEM & Scanning electron microscope
\end{tabular}

\section{Introduction}

Fibre reinforced polymers (FRP) is a composite materials composed of fibre and resin. Currently, FRP is still widely used as a structural component for aircraft element, automotive parts, retrofitting, and other structures include bridges. Polymer based materials was proven has a potential development for sustainability in civil engineering structures. Some advanced characteristics like high strength to weight ratio, low conductivity, and corrosion resistance are among features for which the FRP are increasingly being used in structural applications [1]. All these mentioned advantages give solutions, which aim is to reach low life cycle cost of the structure [2]. The disadvantage of PFRP application is the higher initial cost as compared with conventional materials like steel

Winarputro Adi Riyono, winarputro.adi@pusjatan.pu.go.id | ${ }^{1}$ Institute of Road Engineering, Ministry of Public Works, JL. AH Nasution 264, Bandung, Indonesia. ${ }^{2}$ Institute of Polymer Technology, BPPT, Puspiptek Serpong, Tangerang, Indonesia. 
and concrete. But, this aspect still possibly evolves due to the fact that prices of FRP component materials tend to decrease [3].

Applications for bridges vary starting from the use of FRP materials for beam elements, plate elements, prestressed cable, safety fence, up to as material for bridge retrofit. In the case of bridge retrofit, the used of FRP is mainly for girder or column elements. Usually, FRP sheets are directly applied to deficient elements with additional epoxy as adhesive. Currently, the only guideline available for bridge design is AASHTO 2008 which provide guide specification for design of FRP pedestrian bridges [4]. While, for assessment of structural element properties, the designer could refer to the pre-standard of PFRP for structures [5].

One type of FRP is a pultruded fibre reinforced polymer (PFRP). PFRP is made by using pultrusion process which involving a continuous fabrication of composite materials with constant structural section. PFRP is promising in the future as it gives some solution in modern engineering practice which aim is to reduce time of construction process and to minimise the environmental impact $[3,6]$.

Nevertheless, there is a challenges in the used of PFRP for bridges which seems to be lack of historical precedent structural data. In addition the great variety of fibre and resin combinations and also concern with the scarcity in relation with the characteristics of PFRP which is need to be assessed, make the design of composites structures required accurate experimental determination of the mechanical properties of PFRP [7].

Some progress has been made on experimental PFRP studies. Singh and Chawla [8] conducted a series of experiment tests on $\mathrm{H}$-fibre beam and I-fibre beam and found that composition of fibre used to determine the beam stiffness plays a role on the mechanical characteristics of a fibre beam. Another study focus on the investigation of the effect of temperature and weathering on PFRP. Al-Sulaiman et al. [9] studied the effects of long term natural outdoor and artificial accelerated environmental conditions on the burst resistance of the vinyl-based and epoxy-based glass fibre reinforced filament wound thermoset pipes. The pipes were exposed to natural outdoor and accelerated dry heat conditions. They found that those condition did not produce any noticeable degradation in the resistance of the pipes up to 24 months of natural exposure and up to more than 13 month of dry heat exposure. Mamdouh et al. [10] investigated the bonding characteristics between FRP bars and concrete and found that the behavior is influenced by thermal condition.

So far, characterisation of PFRP are still be an open subject as very few studies are known which aimed at characterising the PFRP as structural element and investigating the effect of environmental condition to the physical and mechanical strength of PFRP. Therefore, a comprehensive investigation is needed to understand the behavior of PFRP in different load states (compression, tension, and flexural). In addition, ageing test will be required to investigate the environmental effect to the PFRP.

There are two main objectives of this study. The first is to obtain the physical and mechanical parameters of the PFRP. Those properties will be compared with the available pre-standard for PFRP to see the applicability of the PFRP for structural elements. The second is to observe the effect of raise in temperature on the mechanical behaviour of PFRP.

In the first part, the description of the experiments is explained briefly. It consists of physical test procedure and mechanical test procedure. Then, a comparison was made between the collected PFRP strength and the minimum requirements according to the pre-standard of PFRP for structures from ASCE 2010 [5]. The pre-standard was developed using principles of probability-based limit states design to provide uniform practice in the design of PFRP structural systems. Finally, a study on the effect of ageing on PFRP through accelerated test will be discussed.

\section{Experiments programme}

The experiments is carried out on a C-shaped PFRP which is usually been used as frame elements for roof of the warehouse structures. In this study, application of C-shaped PFRP for bridge is explored. Figure 1a shows example of planned FRP bridge with C-shaped PFRP as the truss elements. The $\mathrm{C}$-shaped PFRP is manufactured by a composites companies as can be seen in Fig. 1 b. Figure $1 \mathrm{c}$ depict the considered C-beams section which has size of $150 \mathrm{~mm} \times 50 \mathrm{~mm} \times 7 \mathrm{~mm}$ (height $\times$ width $\times$ thickness). The PFRP is made from isophthalic unsaturated polyester resin and reinforced by a continuous roving and chop strand mat. In addition, it contains crosslinker which consists of styren monomer and methyl methacrylate (MMA). The latter gives resistance of the PFRP from ultraviolet.

Experiments test divided into two part which are test to obtain physical properties and mechanical properties of the PFRP. Physical test conducted through determination of fibre content, hardness test (ball indentation), observation of micro-structures in the samples using scanning electron microscope (SEM) and Fourier transform infrared spectroscopy (FTIR). Effect of environmental condition 


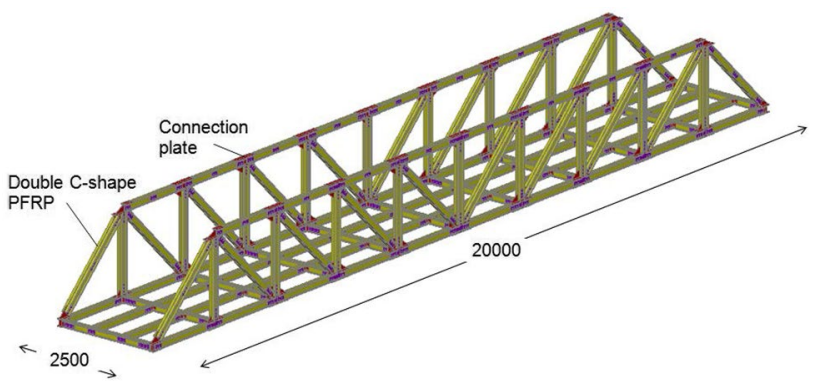

(a)

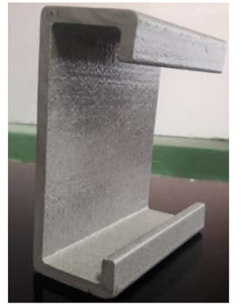

(b)

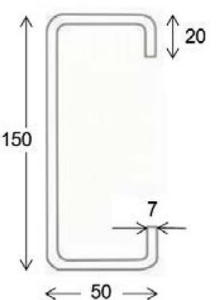

(c)
Fig. 1 C-shaped profile of PFRP as part of bridge element used in this study. a Perspectives of planned FRP truss bridge (all dimensions are in $\mathrm{mm})$. $\mathbf{b}$ C-shaped specimen of PFRP. c C-shaped section of PFRP (all dimensions are in $\mathrm{mm}$ )

investigated through environmental stress cracking resistance (ESCR) test and accelerated ageing test. The mechanical properties are carried out through compression test, tensile test, and flexural test.

\subsection{Physical testing procedure}

\subsubsection{Fibre content}

The fibre content of PFRP was measured by the ignition of samples using method suggested by ASTM D2584 [11]. The quantity of fibre content in the PFRP can be estimated through the help of combustion furnaces. The procedure is firstly by weighing the samples before burning and defined it as initial weight. The specimen is then burned in the furnace with temperature of $550{ }^{\circ} \mathrm{C}$ for about $30 \mathrm{~min}$. After being burned, the specimen is weighed again to find out the lost of mass. The resin content $\left(R_{c}\right)$ can be calculated by using following relationship:

$R_{c}(\%)=\frac{\left(W_{2}-W_{3}\right) \times 100}{\left(W_{2}-W_{1}\right)}$

where $W_{1}$ is the weight of empty pan, $W_{2}$ is the weight of specimen with pan before combustion, and $W_{3}$ weight of specimen and pan after combustion. The fibre percentage can be obtained from the calculated resin content.

\subsubsection{Hardness}

Hardness test is carried out using plastic type procedure according to the ISO 2039-1 [12]. In this test, the indenter is first pressed with a preload of $9.8 \mathrm{~N}$ to a penetration depth of $h_{0}$ as reference level for subsequent test. Then, the test force is applied for a dwell time as defined in accordance with the standard, whereby the indentation depth is measured. The force must be selected from values of $49 \mathrm{~N}, 132 \mathrm{~N}, 358 \mathrm{~N}$, and $961 \mathrm{~N}$ such that the indentation depth measured after a dwell time of $30 \mathrm{~s}$ has a value between 0.15 and $0.35 \mathrm{~mm}$. Ball indentation hardness (HB) is obtained using following equation

$H B=\frac{F_{r}}{\pi d h_{r}}$

where $F_{\mathrm{r}}$ is the reduced test load $(\mathrm{N}), d$ is the diameter of ball indenter $(\mathrm{mm})$, and $h_{\mathrm{r}}$ is the reduced depth of impression $(\mathrm{mm})$.

\subsubsection{SEM}

SEM test is undertaken to observe the morphology of the PFRP as well as the bonding condition between the fibre and resin in the PFRP. The SEM apparatus used in the experiments includes the Energy Dispersive X-ray Spectroscopy (EDS) capabilities. SEM test is performed at high magnifications which generates a high-resolution images and precisely measures very small objects. The observation was carried out on an accelerated voltage of $30 \mathrm{kV}$ as much as three times in different places with $100 \times, 500 \times$ and $1000 \times$ of magnification.

\subsubsection{FTIR}

Fourier-transform infrared spectroscopy (FTIR) is a technique used to obtain an infrared spectrum emission of a solid, liquid, or gas. An FTIR spectrometer collects highspectral-resolution data over a wide spectral range. The fibre and resin composition of the PFRP are identified using attenuated total reflectance method (ATR). ATR is one features of FTIR spectrophotometer to measure surface properties of solid materials.

\subsubsection{ESCR}

The environmental stress cracking resistance (ESCR) test is carried out with the modification of ASTM D1693 [13], 


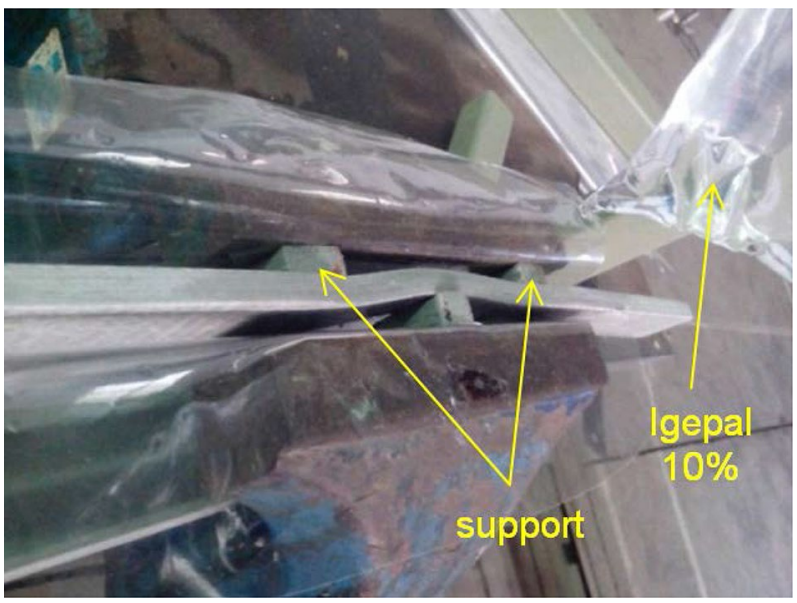

Fig. 2 ESCR test on PFRP sample by bending the specimen laterally

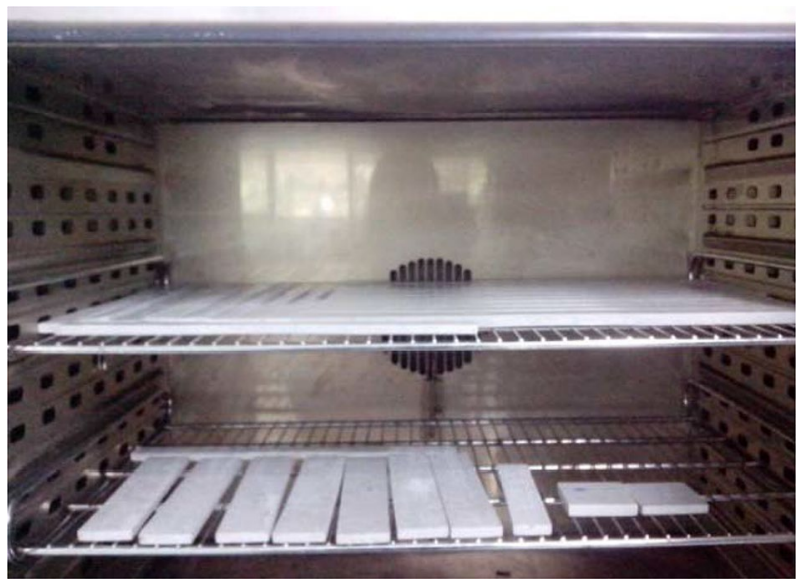

Fig. 3 Samples inside the oven before ageing test

where Igepal $10 \%$ solution and water were used as an ESCR chemicals. In this test, the PFRP specimen is loaded laterally using three point loading boundary condition with a span of $8 \mathrm{~cm}$ and deflected between 2 and $5 \mathrm{~mm}$. During the stressed phase of the specimen, the chemicals solution (Igepal $10 \%$ or water) are dropped on the deformed surface to wet the sample (Fig. 2). Observations are made every minute during the interval $30 \mathrm{~min}$.

\subsubsection{Accelerated ageing test}

Ageing test is undertaken to simulate ageing due to raising of environment temperature. The test is accelerated using oven as an environment exposure. The samples are heated until temperature of $60^{\circ} \mathrm{C}$ and $100{ }^{\circ} \mathrm{C}$ and maintained during 20 days, 40 days, and 60 days. Several mechanical test are then carried out to see the

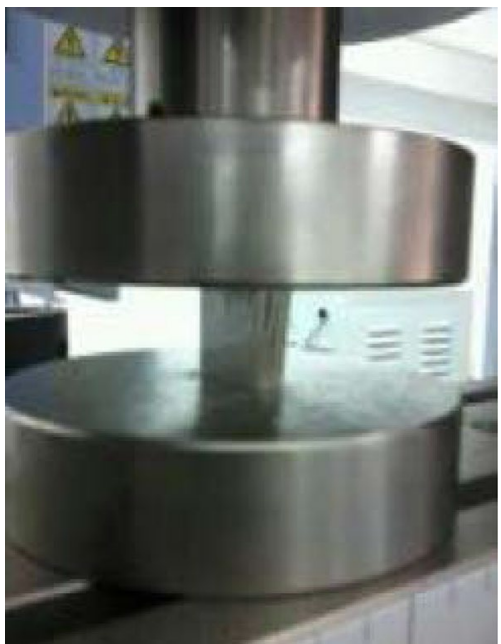

Fig. 4 Compression test on PFRP samples

impact of heating to the samples. Figure 3 shows some samples inside the oven before the accelerated ageing test.

\subsection{Mechanical testing procedure}

\subsubsection{Unconfined compression test}

The compressive strength of the PFRP specimen was measured based on guidelines given in ASTM D3410 [14]. Five specimens each sizing of $30 \mathrm{~mm} \times 20 \mathrm{~mm} \times 7 \mathrm{~mm}$ extruded from PFRP were tested. The specimen was compressed in the direction of the fibre orientation. The direction of loading was chosen to simulate condition of compression member in truss bridge system. The test was performed under a displacement control with loading rate of $1.3 \mathrm{~mm} / \mathrm{min}$ in a temperature of $23.3{ }^{\circ} \mathrm{C}$ and relative humidity $55 \%$. Figure 4 shown specimen under compression test.

\subsubsection{Uniaxial tensile test}

Tensile characterisation is measured using uniaxial tensile test according to ASTM D638 [15]. The test specimen is shaped as dogbone using cutting tools. Figure 5a shows specimen size for tensile test with approximate size of $300 \mathrm{~mm} \times 20 \mathrm{~mm} \times 7 \mathrm{~mm}$. The tension direction is acting parallel to the main fibre orientation. Five specimens with the same size were extruded from PFRP to gain repeatability of the test. The tension tests were conducted on a universal testing machine with $50 \mathrm{kN}$ capacity. The applied displacement rate of crosshead was $5 \mathrm{~mm} / \mathrm{min}$. The specimen was inserted in between

\section{SN Applied Sciences}




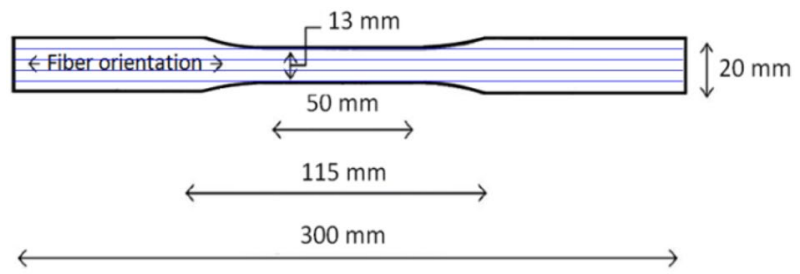

(a)

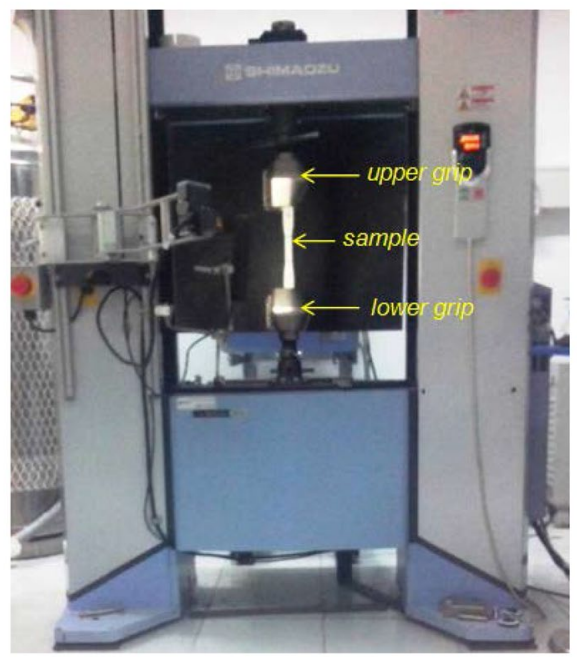

(b)

Fig. 5 Tensile test on FRP samples. a Dogbone shape specimen for tensile test. $\mathbf{b}$ Tensile test apparatus

the pressure wedge grips at both ends as can be seen in the Fig. 5b. The load and strains were recorded via a data acquisition system.

\subsubsection{Three point bending test}

Flexural test performed based on the ASTM D790 [16] specifications. The specimen with size of $130 \times 25 \mathrm{~mm}$ (length $\times$ width) were extruded from the FRP beam (Fig. 6a). Specimen is supported on the steel roller and loaded at the upper center of the beam as shown in the Fig. $6 \mathrm{~b}$. The test was continued until the complete specimen failure, i.e. visible delamination and cracks in ply occurred under the loading. Tests were conducted under a displacement control mode with a displacement rate of $2.9 \mathrm{~mm} / \mathrm{min}$.

For a homogeneous elastic material tested in flexure as a simple supported beam at two points and loaded at the midpoint, the maximum flexural stress $\sigma_{\mathrm{f}}$ in the outer fibre of the test specimen occurs at the midpoint. This stress may be calculated by means of the following equation

$\sigma_{f}=\frac{3 P L}{2 b d^{2}}$

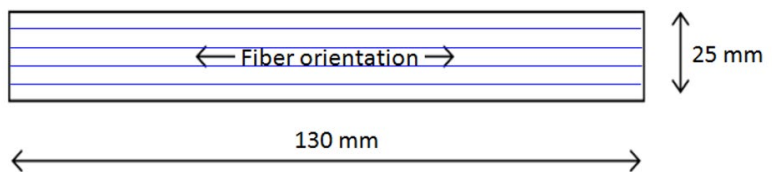

(a)

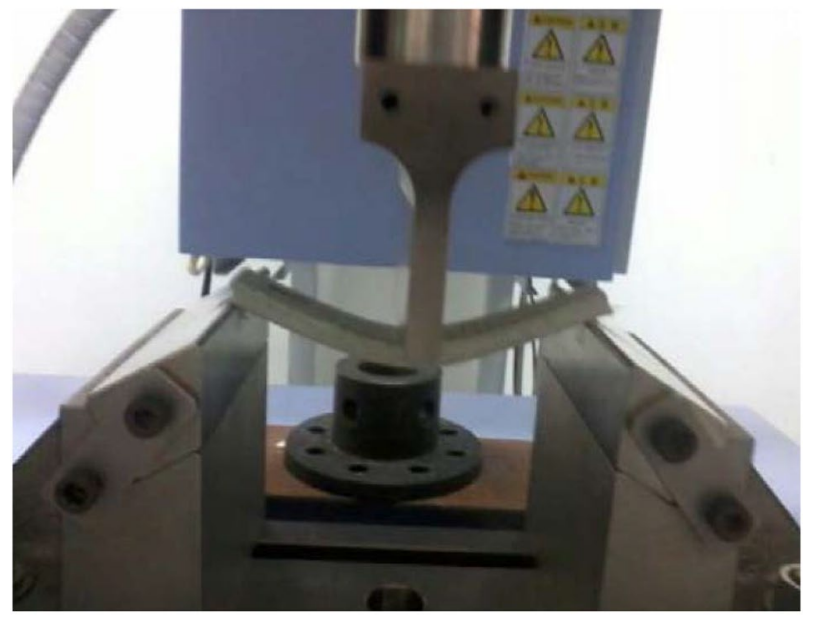

(b)

Fig. 6 Flexural test on FRP samples. a Specimen for flexural test. b Three point bending test on PFRP specimen

where $P$ is the load applied to the beam $(\mathrm{N}), L$ is the support length of the beam $(\mathrm{mm}), b$ is the width of the beam $(\mathrm{mm})$, and $d$ is the depth of the beam $(\mathrm{mm})$.

\section{Results and analysis}

\subsection{Physical properties}

\subsubsection{Fibre content and hardness}

After measuring the lost of mass, it is obtained that the percentage of fibre content is $63 \%$. Thus, the resin content is estimated to be in the range of $37 \%$. This proportion of fibre conform with the minimum total fibre volume fraction of each pultruded FRP structural element which shall not be less than $30 \%$ [5]. According to the ball indentation test, the tested PFRP hardness is about $242 \pm 32 \mathrm{MPa}$.

\subsubsection{Morphology of PFRP}

Figure 7 depict microstructures of the PFRP cutting section through SEM in three different magnification. In the Fig. 7, object with circle shape is the section of glass fibre which is binded by resin matrix. Figure $7 a$ shows image of cutting section of PFRP after $100 \times$ of magnification. 


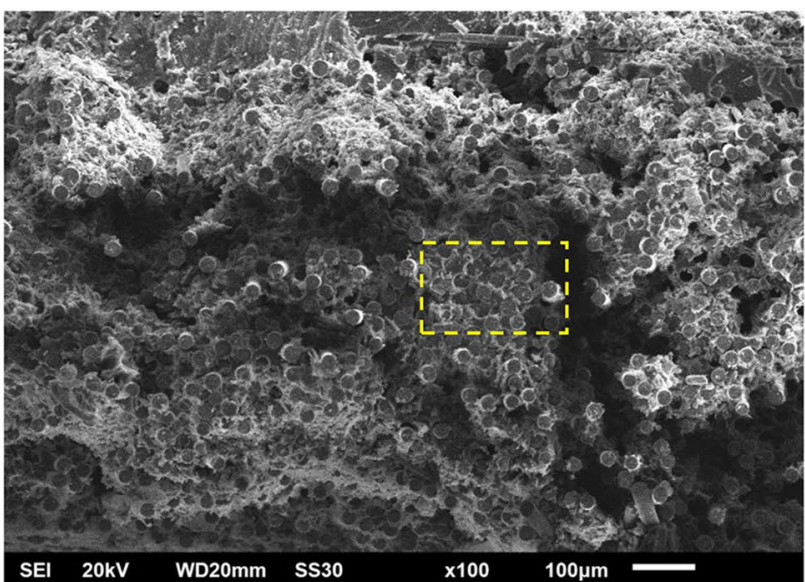

(a)

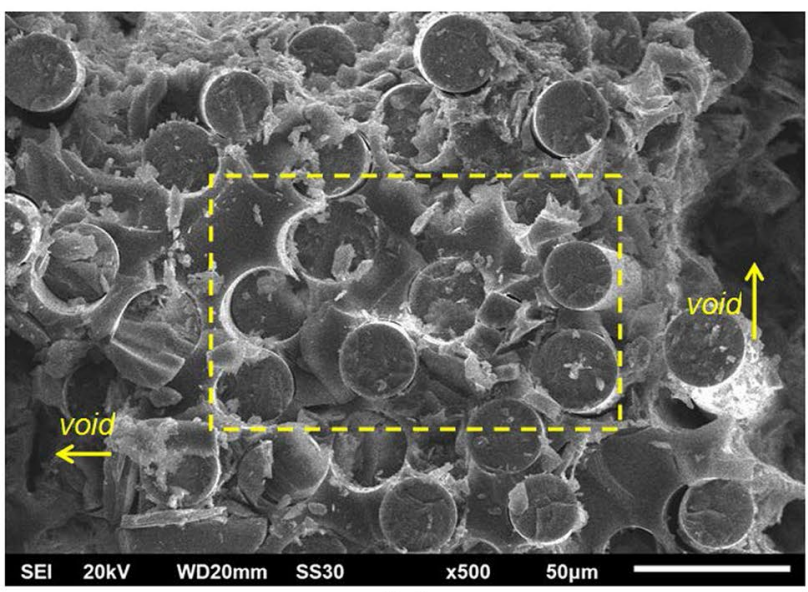

(b)

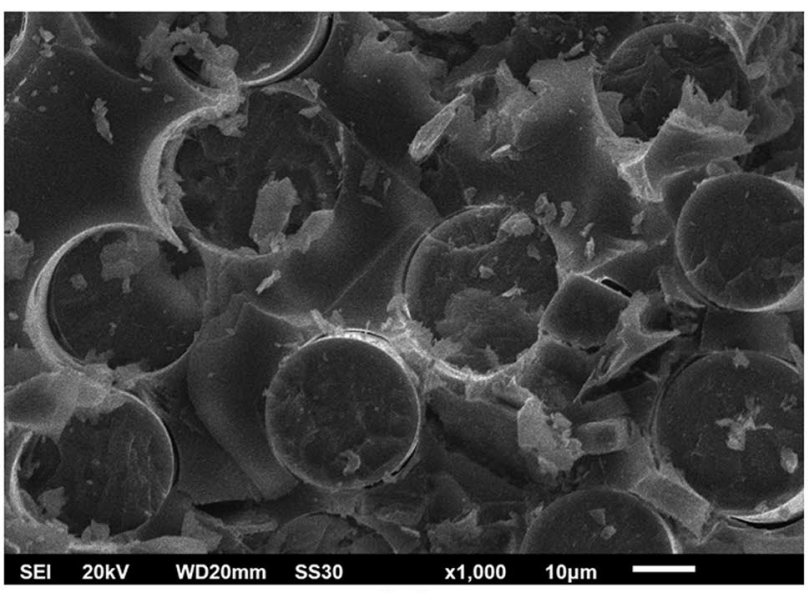

(c)

Fig. 7 Structures of PFRP through SEM. a PFRP with magnification of $\times 100$. $\mathbf{b}$ Detail of the inset part (yellow dashed box in a) with magnification of $\times 500$. $c$ Detail of the inset part (yellow dashed box in b) with magnification of $\times 1000$
Figure $7 \mathrm{~b}$ shows image of PFRP sample in the inset area of Fig. 7 a (yellow dashed line) after $500 \times$ of magnification. It is shown that the actual morphological characterisation in the observed sample shows a good bonding between the polymer matrix and the fibre. At some parts, it is observed that not all of the spaces are filled with the resin and also the fibres (indicated with void in the Fig. 7b). Figure 7c shows the zoom in of the inset in Fig. 7b (yellow dashed line) image after $1000 \times$ of magnification. Showing that the surfaces of the glass fibre is not smooth with some debris of the resin matrix.

\subsubsection{FTIR}

Figure 8 shows the results of FTIR as a fourier spectrum curves with some wave peaks. By identifying wave peaks in the graph, the resin used was identified as an alkyd based group on phthalic anhydride. While, samples of fibre content were identified as mixed material $\mathrm{CaCO}_{3}$ and polysilicate with specific peaks as follows:

$\mathrm{CaCO}_{3}: 1408,875$, and $712 \mathrm{~cm}^{-1}$.

Polysilicate: 952 and $690 \mathrm{~cm}^{-1}$.

\subsubsection{ESCR}

Table 1 shows some observation of the PFRP specimen during ESCR test. After being deflected with the addition of Igepal $10 \%$, the specimen experiences delamination. Other results with water as an ESCR media showing similar results. Showing that intrusion of water on the deformed FRP has a vital role in the FRP performance.

\subsection{Mechanical properties}

\subsubsection{Compression strength}

Figure 9 shows the compression curves of the specimen. The specimen behaves essentially elastic until $90 \mathrm{MPa}$ for sample 2 and $110 \mathrm{MPa}$ for sample 1 before it exhibits hardening and then suddenly failed. The sample 1 has a different trend, where elastic limit reach at $40 \mathrm{MPa}$. There is a sudden stiffness drop at displacement of 0.4 due to early delamination of the specimen. In average, the compressive strength is found to be around of $115 \mathrm{MPa}$. After the failure of the specimen, it was noted that all specimens failed by delamination of fabric layers which is consistent with the failure mechanism reported in Singh and Chawla [8]. 


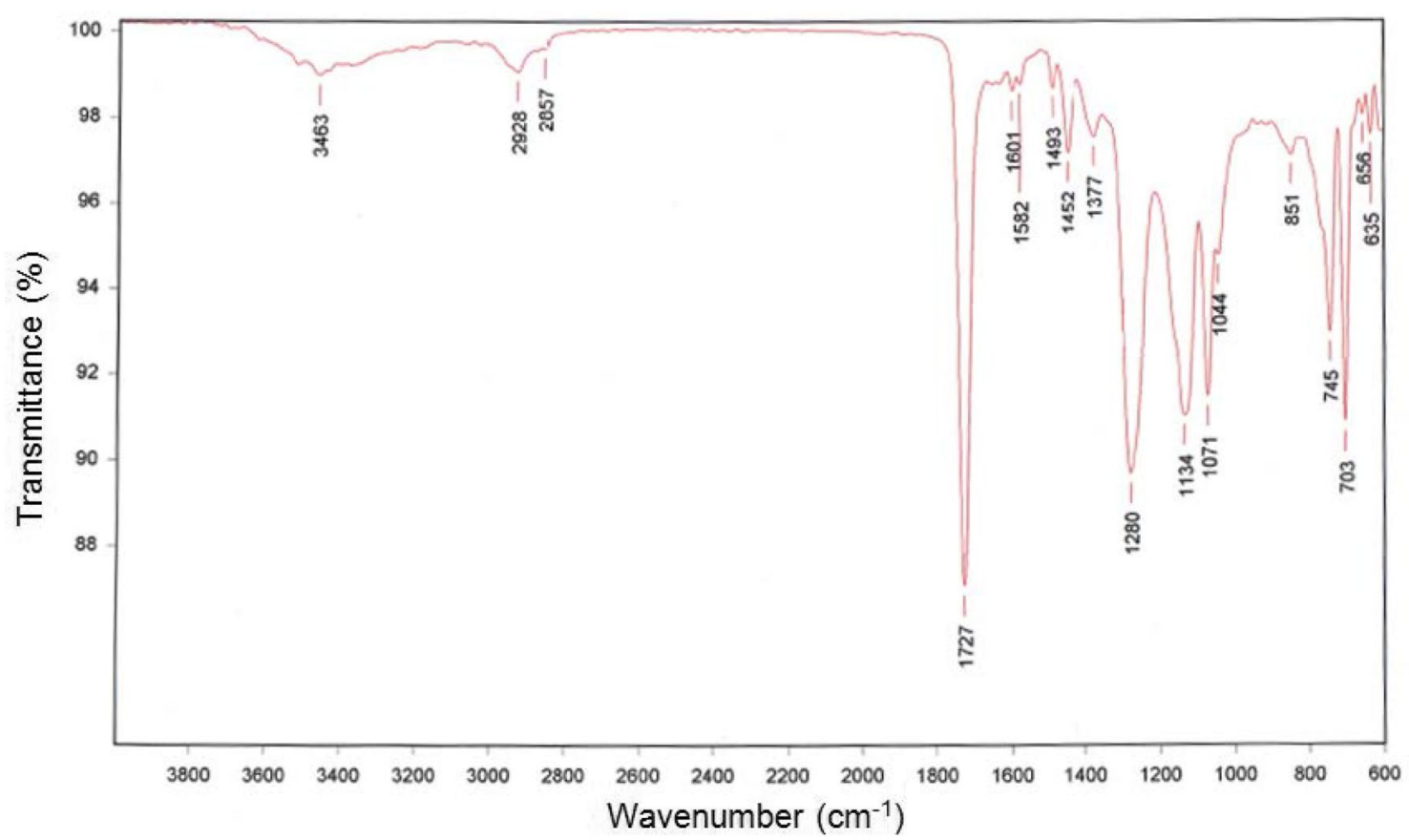

Fig. 8 Fourier spectrum curves of the resin from PFRP samples

Table 1 Observation during ESCR test

\begin{tabular}{llll}
\hline No. & $\begin{array}{l}\text { Deflec- } \\
\text { tion } \\
(\mathrm{mm})\end{array}$ & Fluid & $\begin{array}{l}\text { Duration } \\
\text { (minutes) }\end{array}$
\end{tabular}

\begin{tabular}{rllrl}
\hline 1. & 5 & Igepal 10\% & 7 & Delamination \\
2. & 4 & Igepal 10\% & 15 & Delamination, after $24 \mathrm{~h}$ no change was observed \\
3. & 3 & Igepal 10\% & 25 & Delamination, after $24 \mathrm{~h}$ no change was observed \\
4. & 4 & Water & 8 & Delamination, after 30 min no change was observed \\
5. & 4 & Water & 15 & Delamination, after $2 \mathrm{~h}$ no change was observed \\
6. & 4 & Water & 19 & Delamination, after $1.5 \mathrm{~h}$ no change was observed \\
7. & 4 & Water & 21 & Deflected, delamination, after $1.5 \mathrm{~h}$ no change was observed
\end{tabular}

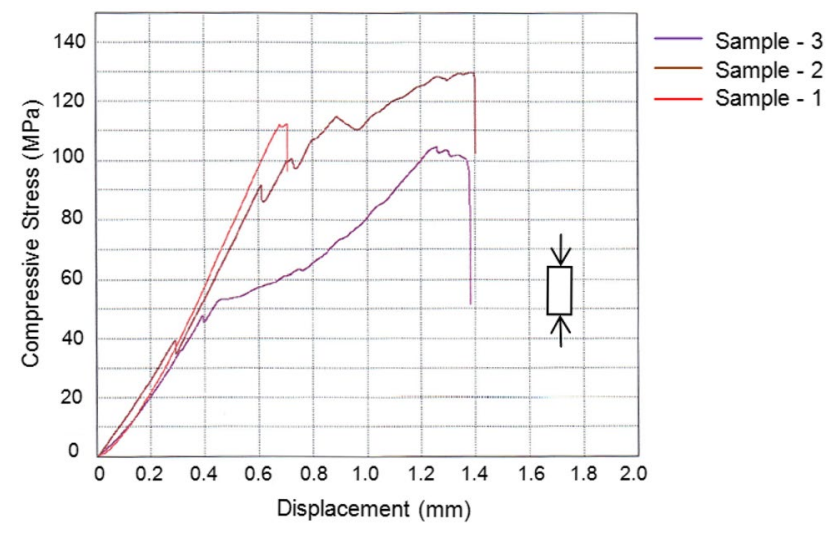

Fig. 9 Compression stress versus displacement of tested PFRP samples

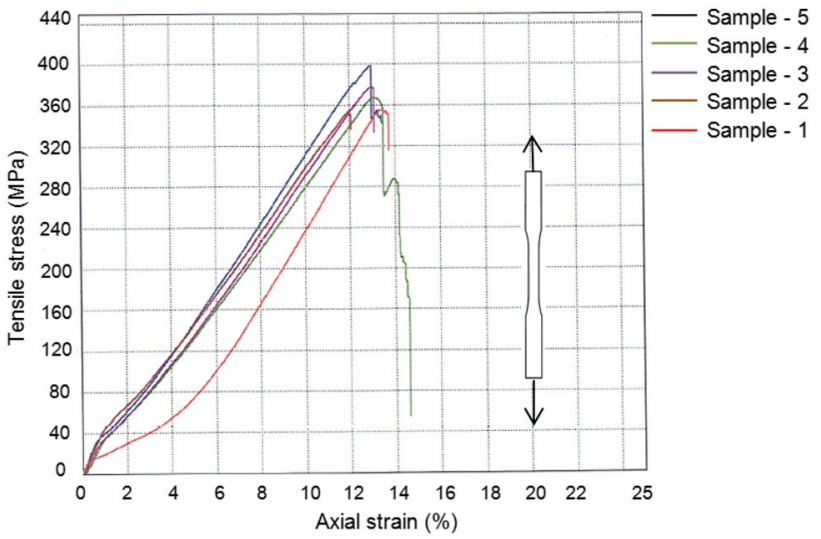

Fig. 10 Tensile stress versus axial strain of tested PFRP samples 
Fig. 11 Flexural stress versus strain of tested PFRP samples

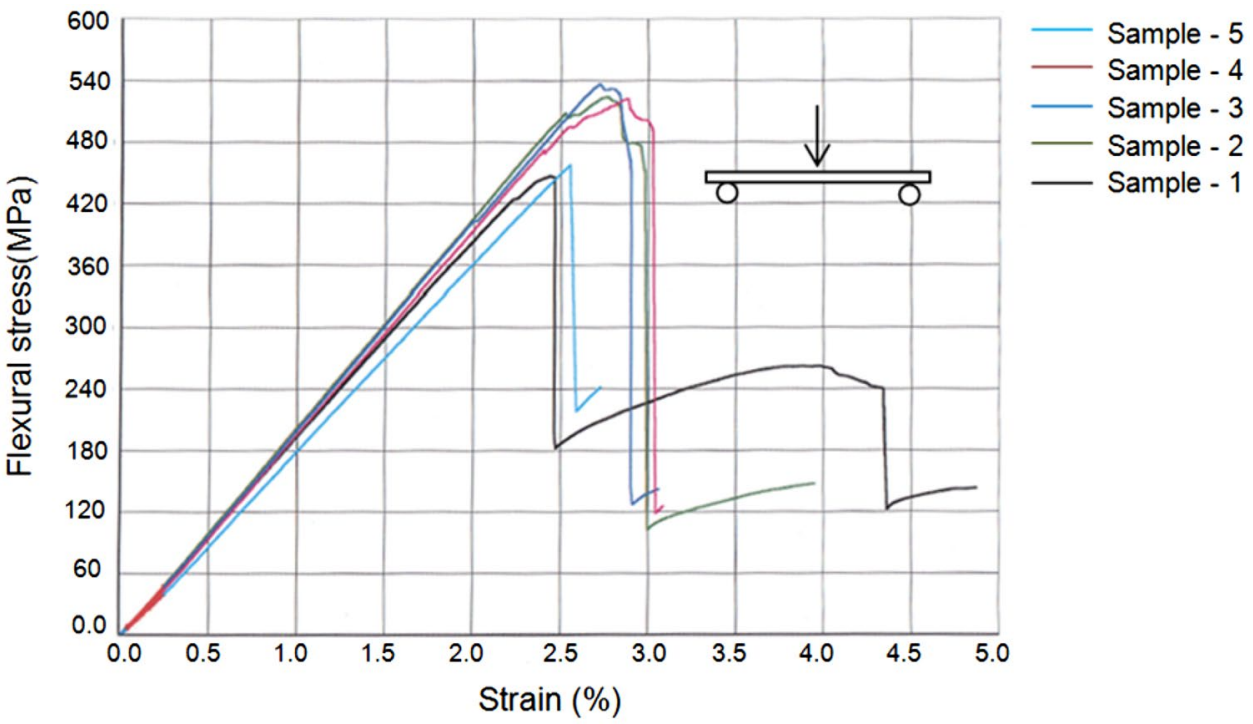

\subsubsection{Tensile strength}

The stress strain curves obtained from tensile test of dogbone specimen are shown in Fig. 10 respectively. Based on Fig. 10, it is noted that all tensile specimens show a linear stress strain behavior before it failed at average level of $350 \mathrm{MPa}$. No ductility was observed for all of the tested specimens. The failure of the samples was sudden and the sound produced was like a gunshot. The failure mode was in the form of delamination of continuous strand mat and cracking in the longitudinal direction as well as transverse direction.

\subsubsection{Flexural strength}

Figure 11 shows the results of flexural test. According to the Fig. 11, the beam specimen behaves linear elastically until stress level of about $360 \mathrm{MPa}$. After these point, it is slightly harden and then fails. The level of failure stress is varies from 440 to $540 \mathrm{MPa}$. After the failure of the specimen, it was noted that all specimens failed by delamination of fabric layers.

\subsection{Comparison with the pre-standard of PFRP for structural elements}

It is important to know the minimum requirements of the material properties for structural members. In this section, those requirements are taken from the pre-standard LRFD for pultruded section. Table 2 shows a comparison between the physical and mechanical characteristics of PFRP according to pre-standard and the current test. In the physical part, the fibre and resin type, and the fibre content already satisfied the minimum requirements PFRP
Table 2 Comparison between properties of tested PFRP with the pre-standard of PFRP for structures [5]

\begin{tabular}{llll}
\hline No. & Properties & C-shaped PFRP & ASCE 2010 [5] \\
\hline 1. & Fibre type & E-glass & Glass type \\
2. & Resin type & Polyester & Thermoset \\
3. & Minimum thickness/ele- & $7 \mathrm{~mm}$ & $9.6 \mathrm{~mm}$ \\
$\quad$ ment & & \\
4. & Fibre content & $63 \%$ & $>30 \%$ \\
5. & Compression strength & $115 \pm 12.9 \mathrm{MPa}$ & $207 \mathrm{MPa}$ \\
6. & Tensile strength & $370,4 \pm 18.5 \mathrm{MPa}$ & $207 \mathrm{MPa}$ \\
7. & Flexural strength & $498.0 \pm 42.1 \mathrm{MPa}$ & $207 \mathrm{MPa}$ \\
8. & Elastic modulus & $20,600 \mathrm{MPa}$ & $20,684 \mathrm{MPa}$ \\
\hline
\end{tabular}

as structural elements. But, the element thickness of PFRP still below the requirements if it is considered as a single element. Therefore, to accommodate this limit in the design, the profile must be redesign to avoid local buckling. The $C$-shaped profile might be doubled and added by a connection plate at the center of the member.

In the mechanical part, three material characteristics which are the tensile strength, flexural strength, and elastic modulus conform with the pre-standard. Whereas, the compression strength still below the pre-standard. Thus, in relation with the design, a careful consideration must be taken in the safety factors for element subjected with compression loading.

\subsection{Effect of ageing through accelerated test}

Table 3 shows compressive strength of PFRP before and after accelerated ageing test. After 20 and 40 days of ageing test with temperature of $60^{\circ} \mathrm{C}$, the specimen tends 
Table 3 Compression strength after ageing at different temperatures

\begin{tabular}{llll}
\hline No. & Condition & Temperature $60^{\circ}(\mathrm{MPa})$ & Temperature $100^{\circ}(\mathrm{MPa})$ \\
\hline 1. & Initial & $162.29 \pm 45.24$ & $162.29 \pm 45.24$ \\
2. & 20 days & $183.92 \pm 12.64$ & $176.47 \pm 18.19$ \\
3. & 40 days & $207.81 \pm 48.83$ & $138.63 \pm 27.20$ \\
4. & 60 days & $188.36 \pm 52.48$ & $148.60 \pm 18.42$ \\
\hline
\end{tabular}

Table 4 Tensile strength after ageing at different temperatures

\begin{tabular}{llll}
\hline No. & Condition & Temperature $60^{\circ}(\mathrm{MPa})$ & Temperature $100^{\circ}(\mathrm{MPa})$ \\
\hline 1. & Initial & $272.03 \pm 14.66$ & $272.03 \pm 14.66$ \\
2. & 20 days & $183.92 \pm 76.14$ & $429.27 \pm 22.19$ \\
3. & 40 days & $207.81 \pm 46.47$ & $187.93 \pm 14.34$ \\
4. & 60 days & $275.57 \pm 19.42$ & $275.66 \pm 12.89$ \\
\hline
\end{tabular}

Table 5 Flexural strength after ageing at different temperatures

\begin{tabular}{llll}
\hline No. & Condition & Temperature $60^{\circ}(\mathrm{MPa})$ & Temperature $100^{\circ}(\mathrm{MPa})$ \\
\hline 1. & Initial & $470.41 \pm 45.24$ & $470.41 \pm 41.09$ \\
2. & 20 days & $517.83 \pm 16.50$ & - \\
3. & 40 days & $469.46 \pm 43.71$ & $409.82 \pm 58.61$ \\
4. & 60 days & $490.35 \pm 18.95$ & $459.81 \pm 27.97$ \\
\hline
\end{tabular}

to increase it's strength. A different observations is seen for the ageing test with temperature of $100^{\circ} \mathrm{C}$, where it can be seen that the compressive strength is still able to raise for 20 days of test, but then it drops after 40 days of ageing test. The increasing of strength might be occured when the cross-linking process in the composite materials is not finished. Cross-linking is a chemical bonding formed between the adjacent chains of a complex molecules such as a polymer. Continued cross-linking reactions are also proven by the mechanical strength of samples made 1 year older is higher than the new sample one [17]. In the other hand, the decrease in the mechanical strength can be caused by the degradation of polymers that occur during ageing test. The cross-linking reaction which has not been completed can cause delamination which results in a decrease in the mechanical properties, even before the product is used.

Effect of ageing to the tensile strength is shown in the Table 4. It can be seen that after 20 and 40 days of ageing test with temperature of $60^{\circ} \mathrm{C}$ and $100^{\circ} \mathrm{C}$, the specimen possible to increase or decrease its strength. This resemble the large variation of the materials properties which implies the inherent heterogeneity of the PFRP samples.
Table 5 shows the effect of ageing test to the flexural strength of PFRP. It can be seen that after ageing test with temperature of $60^{\circ} \mathrm{C}$ and $100^{\circ} \mathrm{C}$, the flexural strength of specimen are still relatively similar.

\section{Conclusion}

In this paper, a series of experiment tests on PFRP samples are reported. The experiments consist of physical and mechanical test. Afterwards, an ageing test was carried out to investigate the temperature effect on PFRP strength. The characterisation results show that temperature and environmental condition has a significant impact on the characteristics of PFRP samples. The raising of temperature tends to decrease the mechanical properties due to polymer degradation. While, heating at a relatively short period of time possible to increases mechanical strength, and further heating time can possibly increase or decrease the PRFP strength. Enhancement of mechanical strength can be caused by polymer cross-linking reactions which takes place after the production of PFRP and accelerated by high temperature. While, the decrease in mechanical strength possibly caused by the degradation of polymers which occur during ageing test. The cross-linking reaction which has not been completed can cause delamination which results in a decrease in mechanical properties, even before the product is used.

Comparison with the pre-standard of PFRP for structures show that in the physical part, the fibre type, resin type, and also the fibre content of the C-shaped PFRP already satisfied the minimum requirements. But, the element thickness of PFRP used in this study is still below the recommendation of the pre-standard if it is considered as a single element. To handle this deficiencies, the PFRP must be redesign to avoid local buckling. The $\mathrm{C}$-shaped profile possibly must be doubled and added by a connection plate at the center of the member to increase the stiffness.

The applicability of this relatively new material technology in the construction industry requires a more detailed study of all the engineering properties, not just limited to the physical and mechanical characteristics, but also included fresh-state properties and performance in the connection which are not included in this study but will be object of further experimental investigations.

Acknowledgements This work was supported by the Institute of Road Engineering (IRE) (Grant No. 13-PPK2-00-1107-F13), Ministry of Public Works, Republic of Indonesia. First author would like to acknowledge the Institute of Polymer Technology for their assistance with material testing and technical advice. The authors expresses their gratitude for the financial support from the IRE. 


\section{Compliance with ethical standards}

Conflict of interest The authors declare that there is no conflict of interest.

\section{References}

1. Kim SH, Yoo JH, Kim HK, Shin KY, Yoon SJ (2018) Failure modes of single and multi-bolted joint in the pultruded fibre reinforced polymer composite members. IOP Conf Ser: Mater Sci Eng 372. https://doi.org/10.1088/1757-899X/372/1/012040

2. Zhang C (2014) Life cycle assessment (LCA) of fibre reinforced polymer (FRP) composites in civil applications. In: Eco-efficient construction and building materials. Life cycle assessment (LCA), eco-labelling and case studies. Elsevier, pp. 565-591. https://doi. org/10.1533/9780857097729.3.565

3. Zyjewski A, Chroscielewski J, Pyrzowski L (2017) The use of fibrereinforced polymers (FRP) in bridges as a favourable solution for the environment. E3S Web of Conferences 17. https://doi. org/10.1051/e3sconf/20171700102

4. AASHTO (2008) Guide specification for design of FRP pedestrian bridges. AASHTO, 444 North Capitol Street, Washington

5. ASCE (2010) Pre-standard for load resistance factor design (LRFD) of pultruded fibre reinforced polymer (FRP) Structures. ASCE

6. Gand AK, Chan TM, Mottram JT (2013) Civil and structural engineering applications, recent trends, research and developments on pultruded fibre reinforced polymer closed sections: a review. Front Struct Civ Eng 7:227. https://doi.org/10.1007/ s11709-013-0216-8

7. Carlsson LA, Adams DF, Pipes RB (2013) Basic experimental characterization of polymer matrix composites materials. Polym Rev 53:277-302. https://doi.org/10.1080/15583724.2013.776588

8. Singh SB, Chawla H (2018) An investigation of material characterization of pultruded FRP H- and I- beams. Mech Adv
Mater Struct 25(2):124-142. https://doi.org/10.1080/15376 494.2016.1250021

9. Al-Sulaiman F, Khan Z, Merah N, Kounain MA, Mehdi M (2010) Effects of weathering on failure pressure of filament-wound GFRP thermoset pipes. J Compos Mater 45(6):645655. https:// doi.org/10.1177/0021998310377933

10. Elbadry MM, Abdalla $H$, Ghali A (2000) Effects of temperature on the behaviour of fibre reinforced polymer reinforced concrete members: experimental studies. Can J Civ Eng 27:993-1004. https://doi.org/10.1139/100-013

11. ASTM D2584-18 (2018) Standard test method for ignition loss of cured reinforced resins. ASTM International, West Conshohocken

12. ISO 2039-1 (2001) Plastics-determination of hardness, part1. Ball indentation method. International Organization for Standardization

13. ASTM D1693-15 (2015) Standard test method for environmental stress-cracking of ethylene plastics. ASTM International, West Conshohocken

14. ASTM D3410, D3410M-16 (2016) Standard test method for compressive properties of polymer matrix composite materials with unsupported gage section by shear loading. ASTM International, West Conshohocken

15. ASTM D638-14 (2014) Standard test method for tensile properties of plastics. ASTM International, West Conshohocken

16. ASTM D790-17 (2017) Standard test methods for flexural properties of unreinforced and reinforced plastics and electrical insulating materials. ASTM International, West Conshohocken

17. Riyono WA (2013) Characterisation of PFRP and design concept for FRP bridges. Ministry of Public Works - IRE

Publisher's Note Springer Nature remains neutral with regard to jurisdictional claims in published maps and institutional affiliations. 